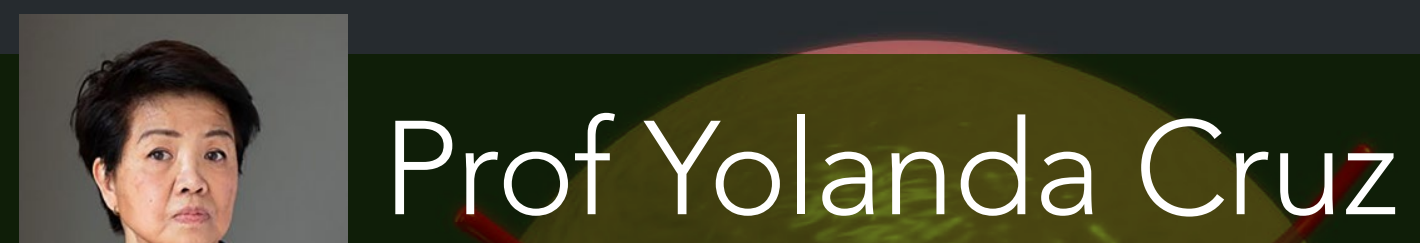

E: ycruz@Oberlin.edu T: +1 (440) 775-8323 W: https://www.oberlin.edu/yolanda-cruz

\title{
Progesterone signalling is involved in marsupial pregnancy
}

\section{Research Objectives}

Yolanda Cruz's current research interests are marsupial reproduction and embryonic development.

\section{Detail}

\section{Address}

Department of Biology

Oberlin College Science Center

Oberlin, $\mathrm{OH} 44074$, USA

\section{Bio}

Yolanda Cruz is Robert S. Danforth Professor of Biology at Oberlin College, Ohio, USA. Her bachelor's and master's degrees are from the University of the Philippines; her PhD degree from the University of California (Berkeley).

\section{Funding}

US National Science Foundation (Grant Nos. 0718404 and 0114832), Oberlin College

\section{Collaborators}

John Lydon (Baylor College of Medicine); Oberlin Research Assistants Jeremy Morrison, Ria Richardson, Jebran Haddad, Nadia Safa, Devon Lycette, Amelia Wright, Chris Pickens, and Troy Spindler.

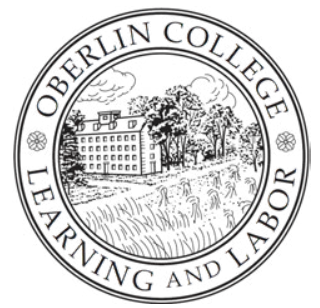

\section{References}

- Cruz YP, Selwood L. (1993) Uterine histology of the dasyurid marsupial, Antechinus stuartii: Relationship with differentiation of the embryo. J. Reprod. Fertil, 99, 237-242.

- Cruz YP, Selwood L. (1997) Histological differences between gravid and non-gravid uteri in the dasyurid marsupial, Sminthopsis macroura (Spencer). J. Reprod. Fertil, 111, 319-325.

- Cruz YP, Selwood L, Morton H, Cavanagh AC. (2001) Significance of serum early pregnancy factor concentrations during pregnancy and embryonic development in Sminthopsis macroura (Spencer) (Marsupialia: Dasyuridae). Reproduction, 121, 933-939.

- Cruz YP, Morton H, Cavanagh AC, Selwood L, Wilson SD, Sasaki M. (2006) Early pregnancy factor in marsupials. Aust. J. Zool, 54, 211-215.

- Yoshida K, Line J, Griffith K, Wooldredge A and Cruz YP. (2019) Progesterone signaling during pregnancy in the lab opossum, Monodelphis domestica. Theriogenology, $136,101-110$.

\section{Personal Response}

\section{Could this work lead to a 'pregnancy test' for marsupials?}

II No, because it would mean removing uterine or ovarian tissues from a living female-not advisable if only testing for pregnancy status. The best pregnancy test is actually the early pregnancy factor (EPF) test, because it can detect pregnancy within a week (or less) in humans, and within 24 hours of a fertile mating in mice. The drawback with EPF testing is it's labour-intensive and thus impractical in nature. 
Biology | Yolanda Cruz

\section{Progesterone signalling is involved in marsupial pregnancy}

Marsupials have a notoriously short pregnanc years, researchers believed that progesterone played no part in this process. However, Professor Yolanda Cruz from Oberlin College, Ohio, USA, has studied pregnancy in the lab opossum (Monodelphis domestica) most of her care case. The researcher unveiled a critical period between day 5 and day 9 , where changes in both progesterone and progesterone receptors are crucial for embryo development. If changes that need to happen during this likely outcome is a complest

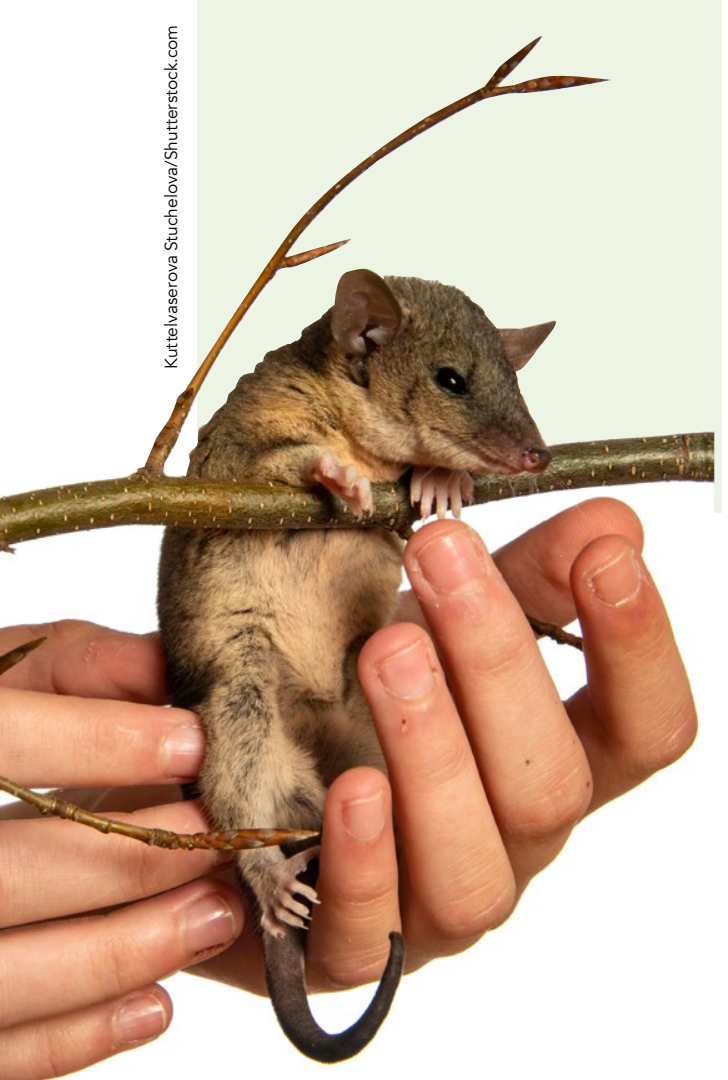

$n$ humans, the establishment of from the foetus to the mother. In simple terms, the foetus 'forces' the ovaries to keep progesterone levels high to ensure everything is ready to promote embryo development. This is known as matern recognition of pregnancy.

For a long time, researchers believed marsupials lacked such a way to regulate After all, it's all over in just a few days. There would appear to be precious little time for any significant changes in progesterone levels. Early studies seem to confirm this belief: pregnant and nonpregnant females showed similar levels of this hormone.

New evidence is coming to light, however. Across a wide range of marsupials, such as the wombat and the Tasmanian devil fluctuations in progesterone levels seem to coincide with crucial changes in both uterus and embryos. Now, Yolanda Cruz, Robert S. Danforth Professor of Biology and her team from Oberlin College, Ohio, want to dig deeper and assess how (Monodelphis domestica) opassum in embryonic development.

\section{OPOSSUM AS A MODEL ANIMAL}

The opossum has become an essential animal model to study the evolution of

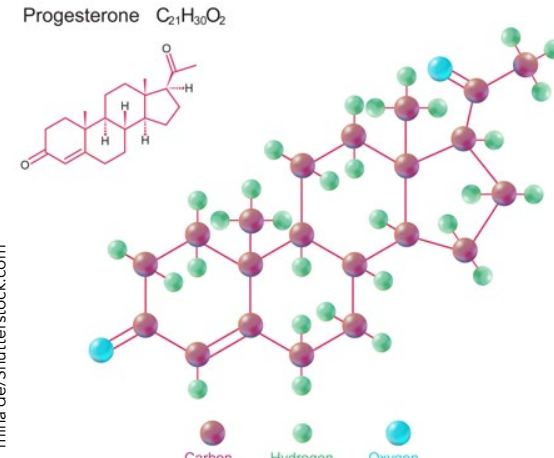

the earliest sign that a viable embryo is developing in the uterus. Indeed, EPF is dged as the earliest sign of a viable pregnancy in both marsupial an placental mammals.

\section{PROGESTERONE SIGNALLING} If EPF signals pregnancy in marsupia then might progesterone actually also have a role in establishing and maintaining pregnancy in these evels, as has been reported for severa marsupial species, might changes in the level of progesterone receptor protein be detected instead? With this in mind, the team decided to compar not only levels of progesterone, pregnant, non-prone receptors in pregnant, non-pregnan

When it came to total progesterone, levels were similar between pregnant, non-pregnant and pseudo-pregnant opossums, but there was a surprising fluctuation during pregnancy which caught the team's attention. In this case, progesterone levels suffered a dip around day 5 , and then gradually increased agai reaching a peak on day 9 .

Interestingly, the same interval was also prominent when it came to progesterone receptors. Up until day 5 expression of these receptors in the uterus was limited, but by day 9 they were firmly established and operation In contrast, their expression in the (uteum) was highest on day 3 but gradually become patchier by day 9 .

In practical terms, although

progesterone levels were not much higher during the brief pregnancy Professor Cruz believes localised progesterone signalling is possible by controlling expression of progesterone receptors. In other words, opossums can make do with a tweak in the level of progesteron receptor activity and not the more energetically expensive increase in progesterone production by the ovary. Pecause the pregnancy is so short, they only need the right receptors expressed in the right location at

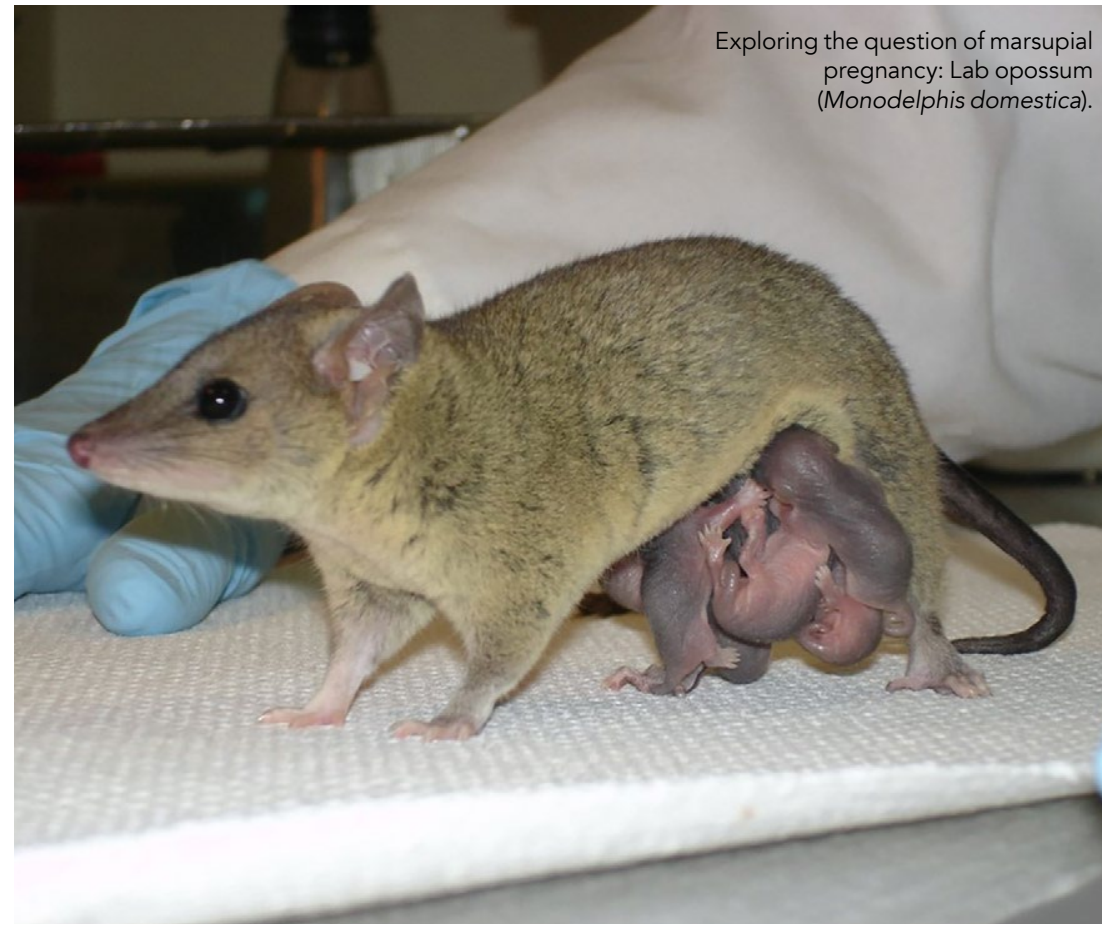

The effects of progesterone signalling may be due to an increase in progesterone receptor expression, and not to changes in circulating or serum progesterone.

progesterone signalling is elevated during pregnancy despite modest (n)

\section{RISK OF EMBRYONIC FAILURE}

\section{(} Window bets 5 ond 5 and dung several changes in progesterone and progesterone receptors happening simultaneously. It also coincides with a curiously long period spent in the blastocyst stage is attained by day 4 of the 280- and 21-day pregnancy, respectively. By comparison, the blastocyst stage takes up to 9 days in the opossum, leaving less than 5 days to form all internal organs and complete the pregnancy.

It thus appears that blastocyst formation by marsupial embryos may during embo develop phase high risk of fallure and thus, complete brood mortality. Losing a few embryos during gestation could happen at any time, but total losses in a short period to recognise the pralure of the mother progesterone levels or faulty receptor vity for example, would mean the end of the pregnancy.

Professor Cruz sees blastocyst formation as a bottleneck during marsupial embryogenesis. A process has to be difficust and thus vulnerable that such a process almost certainly involves complex physiological synchrony, and thus signalling, between mother and embryo. "We now have shown that both EPF and progesteron are likely to have crucial roles in embryo-maternal signalling during marsupial pregnancy," "Professor Cruz concludes, although the nature of in detail." to perturbation. This study suggests 


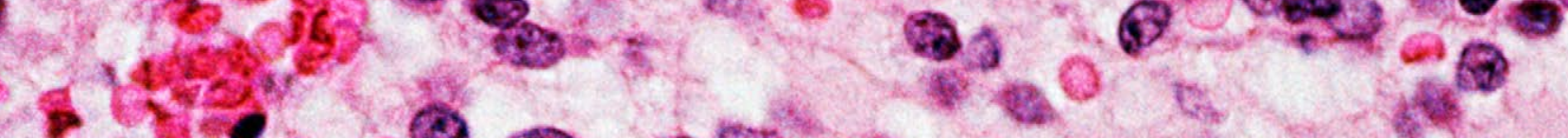

Q 2.:- 0.0 .8

i. A.9. 020

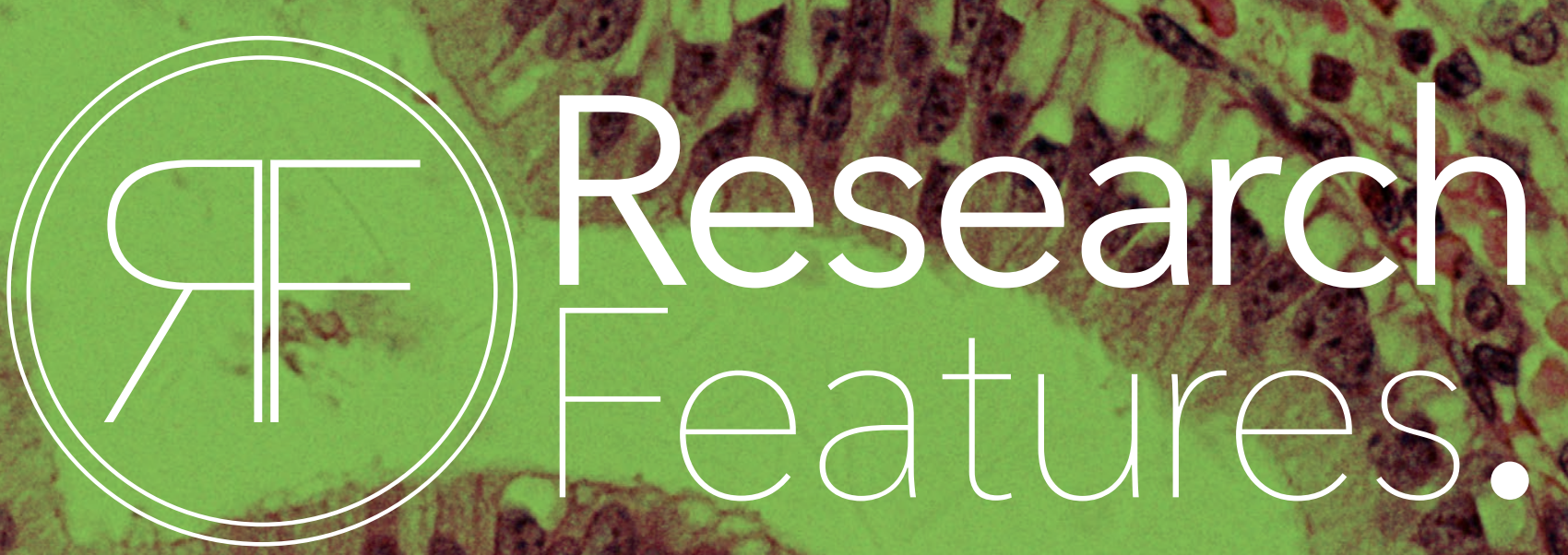

Complex science made beautifully accessible

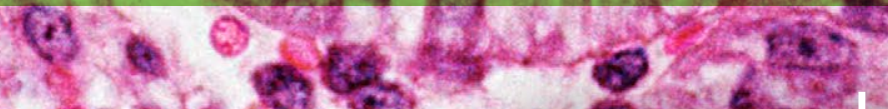
rea es orescarchfeatures.con

6. $\operatorname{lng}_{9}$

9

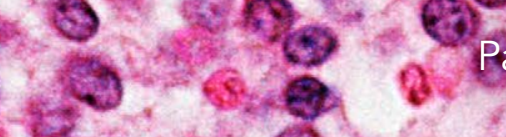

Q8.

(1).

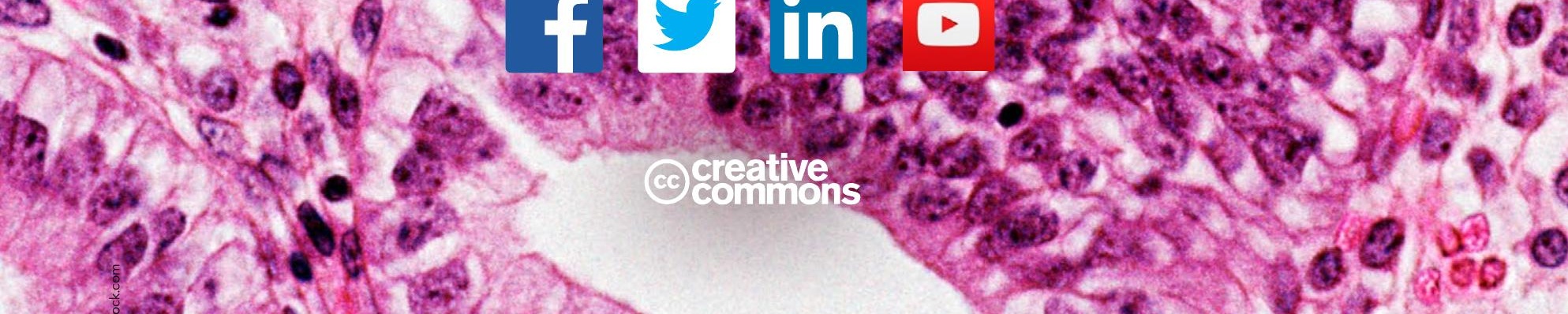

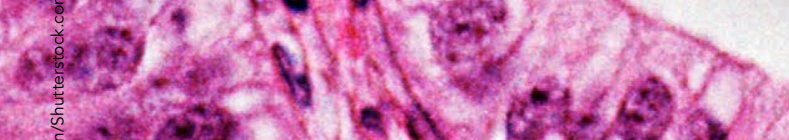

$+\cos 3$

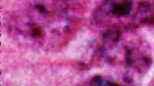

1.

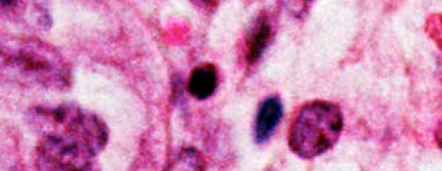

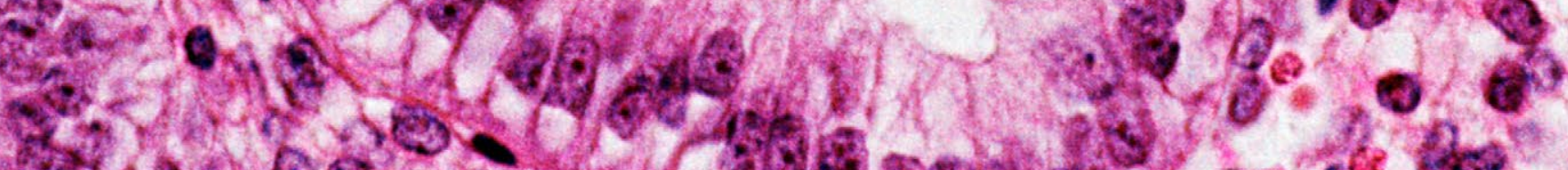

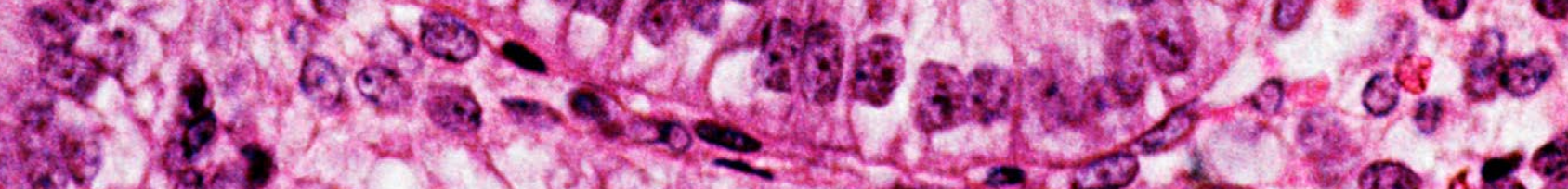

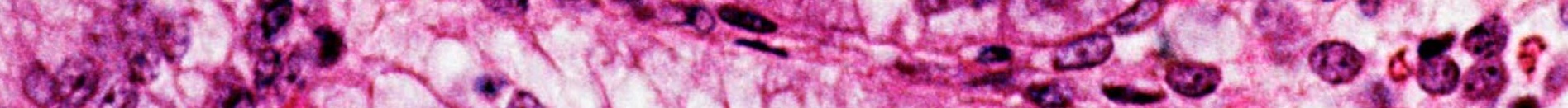

